LeACH, R. H. \& ScotT, W. J. (1959). J. gen. Microbiol. 21, 295-307

\title{
The Influence of Rehydration on the Viability of Dried Micro-Organisms
}

\author{
BY R. H. LEACH* AND W. J. SCOTT \\ Division of Food Preservation and Transport, Commonwealth Scientific and \\ Industrial Research Organization, Homebush, N.S.W., Australia
}

SUMMARY : Freeze-dried preparations of certain organisms may suffer considerable mortality during reconstitution to the wet state. For Vibrio metchnikovi the mortality was greatly decreased by rehydration with small volumes of water, or with various volumes of relatively concentrated solutions of some solutes. Within certain limits, slow dropwise addition of water resulted in higher viable counts than did rapid addition of the same volume of water. In preliminary tests Mycoplasma mycoides and two coliphages were also affected by the volume of water used for rehydration, but no significant effects were observed with nine other bacteria. Comparisons of rehydration at several temperatures showed greatest destruction at $37^{\circ}$ for $V$. metchnikovi, but at $0^{\circ}$ for three other bacteria. The importance of rehydration rates and of exposure to hypotonic solutions is discussed.

Although a great deal of research has been concerned with problems of retaining viability in dried micro-organisms. there has been very little attention given to the rehydration stage of the process. This is somewhat surprising since, whatever the method of drying, rehydration is inevitably required before viability can be assessed. The rehydration procedures actually used by earlier workers have not always been described. Some, including Greiff, Blumenthal, Chiga \& Pinkerton (1954) and Heckly, Anderson \& Rockenmacher (1958), simply restored the water evaporated by adding an equal amount of distilled water. On the other hand, several other fluids have been used, and in amounts which have also varied rather widely. Broth, which was recommended by the Medical Research Council (1958), was used by Stamp (1947), Proom \& Hemmons (1949), Rhodes (1950) and Annear (1956). The volume of broth used by these workers has varied from less than 5 to more than 100 times the volume of the water removed. Fry \& Greaves (1951) rehydrated their cultures with 100 volumes of Ringer solution, Mazur \& Weston (1956) used 2 or 3 drops of a dilute detergent solution for an unspecified amount of dry matter, and Hutton, Hilmoe \& Roberts (1951) used an unspecified volume of dilute tryptose solution. Wasserman \& Hopkins (1957) rehydrated their preparations with dilute solutions, using $c .0 .5 \mathrm{ml} . / \mathrm{mg}$. dry organisms.

The reasons for using the conditions selected by the above workers have, in general, not been supported by comparisons with alternative procedures. Several investigators have, however, reported results of comparisons between different procedures. Hiscox (1945) and Higginbottom (1945) both showed that the plate counts of spray-dried milk powders were increased by making the initial rehydration at $50^{\circ}$ rather than at room temperature, although the

* Present address: The Wellcome Research Laboratories, Beckenham, Kent. 
magnitude of the effects varied somewhat with different types of powder and with different groups of bacteria. Speck \& Myers (1946) showed that spraydried skim-milk cultures of Lactobacillus bulgaricus gave viable counts 1.5 to 5 times greater when rehydration at $50^{\circ}$ as compared with rehydration at $21-25^{\circ}$. They showed that this was true for rehydration with 10 or 100 volumes of water or of $0.5 \%(\mathrm{w} / \mathrm{v})$ sodium citrate, and that the temperature of rehydration did not affect the total microscopic count. Warming after reconstitution was not a substitute for rehydration with fluid at $50^{\circ}$. In contrast, when the preparations had been freeze-dried, rehydration at room temperature resulted in the larger counts. Herrera, Peterson, Cooper \& Peppler (1956) showed that rehydration of dried yeast with cold water caused a loss of viability and an increased leakage of solutes from the cells. These losses did not occur when warm water was used and could also be prevented by partial rehydration with water vapour before adding the cold liquid water (Sant \& Peterson, 1958). The benefits of partial rehydration with water vapour have also been reported for yeast by Mitchell \& Enright (1957) and for fungal spores by Haskins (1957).

Wasserman \& Hopkins (1957) reported that the viable counts of Serratia marcescens were increased several hundred-fold by rehydration with solutions of sodium malate or succinate. These large effects were, however, found with only one of three preparations studied. There is also some evidence that rehydration with complex media increased the recovery of Rous sarcoma virus (Carr \& Harris, 1951) and of poliomyelitis virus (Kraft \& Pollard, 1954).

When, as is usual, rehydration is carried out with liquids, the process is usually completed within a few seconds. The cells are, therefore, subjected to a very rapid change from the dry or near dry conditions of the solid state to the mixture of hydrated colloids and aqueous solutions which makes up the living cell. The complexity of the changes and the speed with which they occur are both matters which make it extremely difficult either to measure or to control the events which take place. Nevertheless, it was considered worthwhile to examine the extent to which variations in methods for adding water to dried cultures may actually cause important differences in viability immediately after rehydration. Such an investigation might be expected to reveal some general principles which would be a useful guide for developing procedures to cause the least possible damage to micro-organisms during rehydration. The present paper reports some of the results obtained when various rehydration procedures were applied to several test organisms.

\section{METHODS \\ Organisms and preparation of cultures}

Most of the experiments were carried out with a strain of Vibrio metchnikovi (NCTC 8443), an organism which is rather sensitive to drying. Suspensions of this organism were obtained from surface growth on brain theart infusion agar after $18 \mathrm{hr}$. at $37^{\circ}$, or from brain theart infusion liquid medium shaken for $18 \mathrm{hr}$. at $30^{\circ}$. After harvesting, organisms were concen- 
trated by centrifugation and resuspended in the fluid in which the organisms were to be dried. Except where otherwise stated, this fluid was a $2.5 \%$ (w/v) solution of Difco peptone containing 0.5 M-sorbitol.

\section{Drying of suspensions}

Replicate ampoules containing $0.2 \mathrm{ml}$. were dried for $4 \mathrm{hr}$. as described by Scott (1958). For a few experiments the specimens were dried in the equipment of Mellor \& Ohye (to be published). After drying, the ampoules were stored at $-20^{\circ}$ over $\mathrm{P}_{2} \mathrm{O}_{5}$ in vacuo and from time to time a sufficient number was withdrawn to carry out a particular rehydration experiment. Precautions were taken to avoid condensation of water on the ampoules by ensuring that they had warmed to room temperature before the desiccator was opened.

\section{Rehydration of suspensions}

Rehydration was normally carried out by pipetting the required volume of test fluid directly into an ampoule. For amounts of rehydration fluid larger than 2.0 ml. it was necessary to use a Pasteur pipette, washing the dried culture as quickly as possible into the required volume held in a separate testtube. After a further 2-5 min., the rehydrated material was further diluted in sufficient $0 \cdot 15 \mathrm{M}-\mathrm{NaCl}$ to give the nearest tenfold dilution in terms of the original undried suspension. Closer control than this of the period of exposure to the initial rehydrating fluid was not attempted, preliminary experiments having indicated that changes in viability which might occur between the above times would generally be very small in relation to the gross changes occurring almost instantaneously upon rehydration. After further tenfold dilutions in $0.15 \mathrm{M}-\mathrm{NaCl}$, viable counts were made. Saline of this approximate strength $\left(0.15 \mathrm{M}-\mathrm{NaCl} ; a_{\mathrm{w}} 0.995 ; a_{\mathrm{w}}=\right.$ thermodynamic activity of water in the solution) was shown to be a suitable diluent for viable counts of Vibrio metchnikovi (Marshall \& Scott, 1958). Unless otherwise noted rehydration was carried out at room temperature $\left(18-25^{\circ}\right)$.

\section{Viable counts}

For Vibrio metchnikovi viable counts were performed by the technique of Miles \& Misra (1938) or by the pour-plate technique with nutrient agar adjusted as described by Scott (1953) to $a_{w} 0.990$ with a salt mixture with the ratio $\mathrm{NaCl}: \mathrm{KCl}: \mathrm{Na}_{2} \mathrm{SO}_{4}: \mathrm{MgCl}_{2}:: 5: 3: 1: 1$ mole. Good agreement between counts from successive dilutions was obtained with this medium, which was similar in composition to those reported by Marshall \& Scott (1958) to give the greatest plate count for $V$. metchnikovi. These workers found that the plate count of this organism was remarkably sensitive to variations in the ionic and osmotic properties of the medium used. Colonies were counted after $18 \mathrm{hr}$. at $37^{\circ}$ for the Miles \& Misra method, and after 2-3 days at $37^{\circ}$ for the pour-plate method. 


\section{RESULTS}

\section{Experiments with Vibrio metchnikovi}

Rehydration with liquid water. The effects of reconstituting replicate ampoules of dried cultures of Vibrio metchnikovi with different volumes of water are shown in Fig. 1. Each ampoule before drying held $\mathbf{0 . 2} \mathrm{ml}$. suspension, containing about $10^{9}$ viable organisms $/ \mathrm{ml}$, and with a dry-matter content of c. $25 \mathrm{mg}$./ampoule, depending on the composition of the suspending fluid. Increasing the amount of water used for rehydration from 0.25 to $16 \mathrm{ml}$. caused the viable counts to decrease by factors of a hundred to more than a thousand (Fig. 1). Similar results were obtained with cultures dried in different suspending fluids and by different methods. With one of the suspensions, rehydration with less than $\mathbf{0 . 2 5} \mathrm{ml}$. water also resulted in poorer recovery.

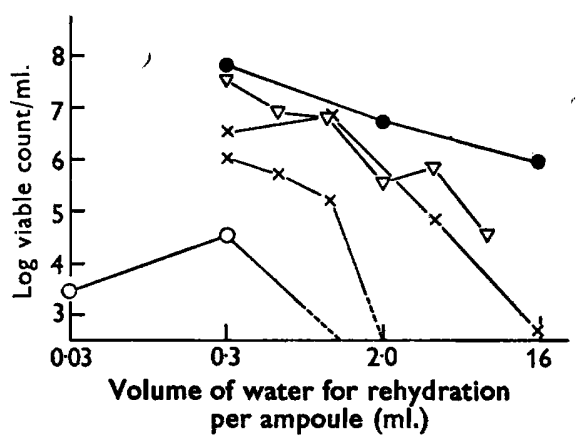

Fig. 1

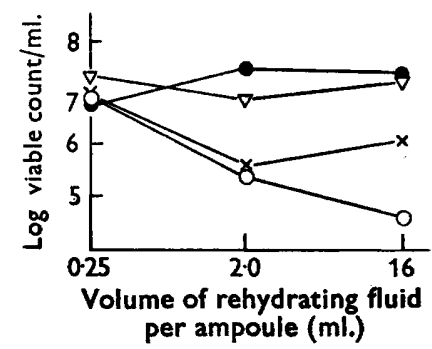

Fig. 2

Fig. 1. Survival of dried Vibrio metchnikovi as a function of the volume of water used for rehydration. Viable counts from $0.2 \mathrm{ml}$. samples of cultures dried in various suspending fluids and reconstituted with varied volumes of water. Suspending fluids: $\times, 0.5 \mathrm{~m}-$ glucose in papain digest broth; $\nabla, 0.5 \mathrm{M}$-sorbitol in $2.5 \%$ peptone; $0,0.5 \mathrm{M}$-sucrose in $2.5 \%$ peptone (all dried by standard method); $0.5 \mathrm{M}$-sorbitol in $2.5 \%$ peptone (dried by alternative method).

Fig. 2. Survival of dried Vibrio metchnikovi as a function of the volume of water or other fluids used in rehydration. Viable counts from $0.2 \mathrm{ml}$. samples of a culture, dried in $0.5 \mathrm{M}$-glucose in papain digest broth, and reconstituted with varied volumes of: 0 , $0.5 \mathrm{~m}$-glucose in papain digest broth; $\nabla$, papain digest broth; $x, 0.5 \mathrm{M}$-glucose; $O$, distilled water.

Rehydration with aqueous solutions. When replicate ampoules were rehydrated with different volumes of certain aqueous solutions the deleterious effect of using larger volumes was no longer observed. Results of a typical experiment are shown in Fig. 2 from which it may be seen that rehydration in papain digest broth with or without $0.5 \mathrm{M}$-glucose gave viable counts which were substantially independent of the volume of fluid used. On the other hand, for $0.5 \mathrm{M}$-glucose and for water itself, the viable counts were decreased when either 2 or $16 \mathrm{ml}$. of fluid were used. All four rehydration fluids gave similar counts when only $0.25 \mathrm{ml}$. was used. The effects of rehydration with different volumes, therefore, differed appreciably for different fluids. In an attempt to find some explanation for these differences the effects of the nature 
and concentration of the solute were studied in experiments in which the volume of fluid was maintained at $2.0 \mathrm{ml}$.

Some results for experiments of this type are shown in Fig. 3, from which it may be seen that rehydration in five types of solution was tested at each of several concentrations. As two of the solutions were mixtures and one of these consisted of a complex mixture of solutes, the concentrations have been expressed on the $a_{\mathrm{w}}$ scale (25.) using the data of Scott (1953) for the mixtures, of Robinson \& Stokes (1955) for sodium sulphate and sucrose, and of Scatchard, Hamer \& Wood (1938) for glycerol. For each of the materials other than glycerol there was evidence of an optimum concentration at which the viable count of the rehydrated bacteria was greatest. Whereas this optimum was at c. $\mathbf{0 . 9 8 5} a_{\mathrm{w}}$ for sucrose solutions, it was $0.98 a_{\mathrm{w}}$ for sodium sulphate, close to $0.97 a_{\mathrm{w}}$ for brain theart broth and $c .0 .96 a_{\mathrm{w}}$ for the mixed salts. For the glycerol solutions an optimum concentration was not detected, the greatest viability being obtained by using the most concentrated solution. For $0.92 a_{\text {w }}$ at $25^{\circ}$ the glycerol is 4.44 molal or $c .29 \%$. It may be noted that when solutions of $0.92 a_{\mathrm{w}}$ were used for rehydration, glycerol was the best of the substances tested, whereas in relatively dilute solution it gave very much smaller recoveries of viable bacteria than the other substances used. It may also be seen that the maximum recovery after rehydration in brain + heart infusion was more than a million times greater than when water was used. Results comparable to those shown in Fig. 3 were also obtained with other substances. For instance, rehydration with glucose solutions gave the greatest count when the glucose solution was of $a_{\mathrm{w}} \mathbf{0 . 9 7}$. For glycine the optimum was at c. $0.98 a_{\mathrm{w}}$, and for magnesium chloride at $0.985 a_{\mathrm{w}}$. For these three compounds, however, the maximum counts were between only 0.2 and $2.0 \%$ of the greatest value obtained after rehydration in concentrated brain + heart broth. Rehydration in arabinose solutions gave poor recoveries of viable organisms; with urea solutions very few living organisms were detected at all concentrations up to the maximum tested $\left(0.92 a_{w} ; 5.4\right.$ molal).

In view of these results it was of interest to compare the effect of the same range of concentrations of solutes on the viability of undried organisms, of organisms previously dried but already reconstituted before treatment, and of dry organisms. Samples $(0.2 \mathrm{ml}$.) of a single suspension of Vibrio metchnikovi were therefore treated in three different ways. First, individual samples were transferred into $20 \mathrm{ml}$. of each of the test solutions, and after $2 \mathrm{~min}$. diluted in $0.15 \mathrm{M}-\mathrm{NaCl}$ for viable counts. The remaining $0.2 \mathrm{ml}$. samples of suspension were freeze-dried and half of these were rehydrated directly in $20 \mathrm{ml}$. of each of the various solute concentrations, then after 2 min. diluted in saline and plated. The other samples were first reconstituted to their original $(0.2 \mathrm{ml}$.) volumes with distilled water, and then treated in the same manner as the undried suspensions. Separate experiments of this kind, each at least in duplicate, were carried out with sodium chloride, sucrose and concentrated brain + heart broth at each of eight concentrations giving $a_{\mathrm{w}}$ values between 0.999 and 0.90 . As the results with these three materials were very similar, only those for sodium chloride solutions are recorded (Fig. 4). 
The organisms which had not been dried proved to be rather more resistant to exposure to dilute solutions, dilution in water causing a mortality of about $90 \%$ under the conditions of the experiments. For dried organisms immediately transferred to $20 \mathrm{ml}$. of water the apparent mortality was c. $99.99 \%$, and c. $99.9 \%$ when the dried organisms had first been rehydrated with $0.2 \mathrm{ml}$. water. The principal conclusion from these experiments is that the mortality caused by the rehydration of Vibrio metchnikovi in large volumes of water or dilute solutions is largely a consequence of exposing the freshly rehydrated organisms to dilute solutions. As previous rehydration in a small volume of water decreased, but by no means abolished, the mortality occasioned by exposing the organisms to dilute solutions, it follows that the events during the early stages of rehydration are of some importance. This conclusion is also supported by the greater viable counts obtained by direct rehydration with $20 \mathrm{ml}$. of these solutions when the $a_{\mathrm{w}}$ value was between $c .0 .96$ and 0.99 .

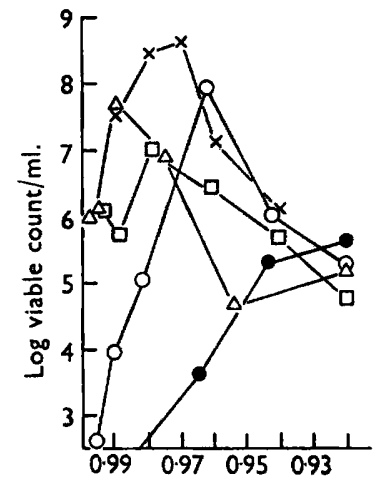

$a_{w}$ of rehydrating solutions

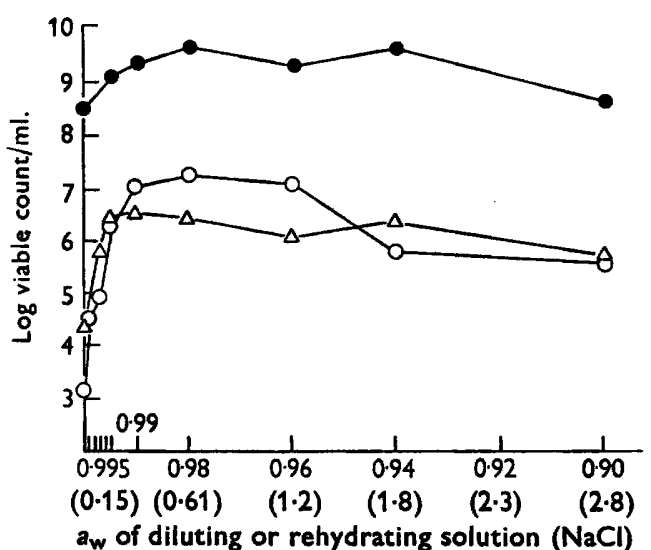

(Figures in brackets give concs. in terms of molality)

Fig. 3

Fig. 3. Survival of Vibrio metchnikovi as a function of the concentration of the rehydrating solution. Viable counts from $0.2 \mathrm{ml}$. samples of a culture dried in $0.2 \mathrm{M}$-sorbitol in $2.5 \%$ peptone, and reconstituted with a fixed volume $(2.0 \mathrm{ml}$.) of solutions of several solutes at different $a_{w}$ values. Solutes: $O$, mixed electrolytes solution ( $\mathrm{NaCl}: \mathrm{KCl}: \mathrm{Na}_{2} \mathrm{SO}_{4}: \mathrm{MgCl}_{2}$ in molecular ratio 5:3:1:1); $\triangle$, sucrose; $Q$, glycerol; $x$, brain + heart broth; $\square, \mathrm{Na}_{2} \mathrm{SO}_{4}$.

Fig.4. Survival of undried, dried, and reconstituted Vibrio metchnikovi suspensions following transfer to $\mathrm{NaCl}$ solutions of different $a_{\mathrm{w}}$ values. Mean viable counts from duplicate $0.2 \mathrm{ml}$. samples of a suspension in $0.5 \mathrm{M}$-sorbitol in $2.5 \%$ peptone, transferred to $20 \mathrm{ml}$. of $\mathrm{NaCl}$ solutions after various preliminary treatments : 9 , no preliminary treatmentundried suspension diluted directly in $\mathrm{NaCl}$ solution; 0 , freeze-dried suspension$\mathrm{NaCl}$ solution added to dry cells; $\triangle$, freeze-dried suspension-reconstituted first in $0.2 \mathrm{ml}$. water, then diluted in $\mathrm{NaCl}$ solution.

In view of the considerable differences in the performance of different types of solutions (Fig. 3) some comparative tests were made with a series of six polyhydric alcohols, each compound being tested at six concentrations between 0.25 and 5.0 molal. Three such experiments were made, each showing similar trends; the combined results are summarized in Fig. 5 from which considerable differences in performance between solutes of differing molecular weight 
are evident. For the two hexitols the best recovery was obtained after rehydration in 1.0 molal solutions, which resulted in counts more than 100 times greater than those given by rehydration in water alone. For the 4- and 5-carbon compounds, erythritol and ribitol, the optimum concentrations were rather higher, being between 1-2 and 2-3 molal, respectively, and the maximum counts for these solutes were only 25-30 times better than for the water control treatments. With the smallest molecules (ethyleneglycol, glycerol) none of the concentrations tested was superior to water alone, the higher concentrations of glycerol being less effective than in the experiment shown in Fig. 3.

Although the differences associated with the different molecular weights of the solutes are not explained by these experiments, it is conceivable that the effects were at least partly connected with differences in the rates at which water entered the cells. During rehydration molecules which enter the cell more

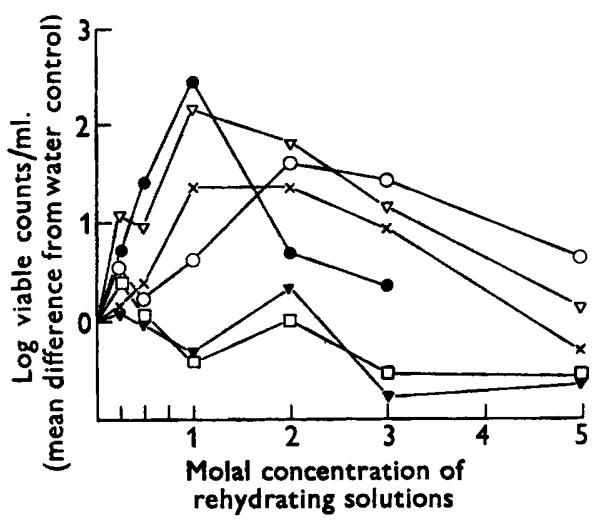

Fig. 5

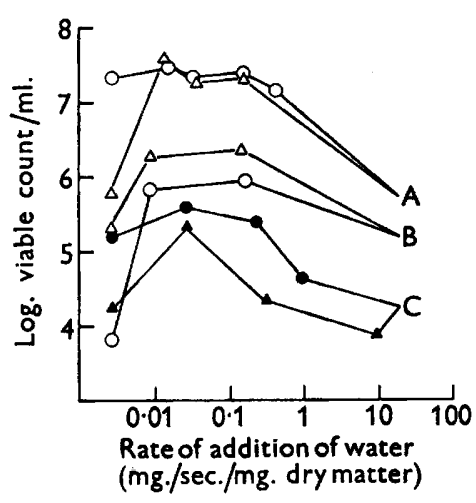

Fig. 6

Fig. 5. Survival of dried Vibrio metchnikovi as a function of the concentration of the rehydrating solution, for solutes of increasing molecular weight. Pooled results of three separate experiments. Viable recovery expressed as the average deviation from the mean of viable counts given by distilled water, after reconstitution of $0.1 \mathrm{ml}$. samples of suspensions, dried in $0.5 \mathrm{M}$-sorbitol in $2.5 \%$ peptone, with a fixed amount $(1.0 \mathrm{ml}$.) of varied concentrations of a series of polyols : $\nabla$, sorbitol; $\theta$, mannitol; $x$, ribitol; $O$, erythritol; $\square$, glycerol; $\nabla$, ethylene glycol.

Fig. 6. Survival of dried Vibrio metchnikovi as a function of the rate of rehydration. Viable counts from three experiments, $A, B$ and $C$, in which $0.2 \mathrm{ml}$. samples of culture dried in $0.5 \mathrm{M}$-sorbitol in $2.5 \%$ peptone were reconstituted with $0.25 \mathrm{ml}$. distilled water added as drops delivered at various rates. Experiments $A$ and $B$ were carried out with the same dried culture but stored for different periods. In expt. $C$, the counts are the means from duplicate samples. The common maximum rehydration rate of $20 \mathrm{mg}$. water/sec./ mg. dry matter is the approximate value given by direct pipetting of $0.25 \mathrm{ml}$. water to a dried sample. Drop size: $\triangle, 1 / 35 \mathrm{ml}$; $O, 1 / 270 \mathrm{ml}$.; $\triangle, 1 / 28 \mathrm{ml}$.;, $1 / 200 \mathrm{ml}$.

slowly than water molecules will temporarily accumulate at the external boundary of the cell, and there compete for water molecules as they enter the cell. Gradients so generated in the external solution would, of course, disappear as rehydration approached completion. The probability of obtaining a local solute concentration sufficient to cause an appreciable decrease in the 
water flux will be a function of the solute concentration at a distance, and an inverse function of the rate at which the solute molecules themselves enter the cell. Such a view is in accord with the experimental facts summarized in Fig. 5, and with the different rates at which members of this series of solutes penetrate into bacteria (Mitchell \& Moyle, 1956). Attempts to obtain more direct evidence for the influence of rehydration rates are described in the following section.

Rehydration at various rates. Some attempts were made to control the rate of rehydration of dried cultures of Vibrio metchnikovi with water added in the vapour phase but with the rates realized, this procedure was highly lethal. The maximum rehydration rate obtained was about $10^{-3} \mathrm{mg}$. water/ sec./mg. dry matter. The extreme slowness of rehydration by this method probably accounted for its detrimental effect.

Considerably faster rates were obtained by adding water in the form of a mist from a glass atomizer. Rehydration of dried Vibrio metchnikovi suspensions with mists delivered at different rates suggested that slow rehydration may produce a recovery several times greater than that from direct rehydration with liquid water. There was, moreover, some indication of an optimum rehydration rate of the order of $10^{-2} \mathrm{mg}$. water $/ \mathrm{sec} . / \mathrm{mg}$. dry matter. These same trends were demonstrated more conclusively however in the following experiments in which water was added in the liquid phase as small drops.

By fitting capillary tubes of suitable bore to the delivery tip of a burette, rehydration could be carried out at varying rates with drops of a required size. When $\mathbf{0 . 2} \mathrm{ml}$. replicate samples of dried Vibrio metchnikovi suspension were reconstituted with $0.25 \mathrm{ml}$. distilled water added as drops in this manner, the recovery of viable organisms was markedly increased by slower rates of addition, for a wide range of drop-sizes (Fig. 6). The best recovery was produced by rehydration at $10^{-1}$ to $10^{-2} \mathrm{mg}$. water/sec./mg. dry matter. It was again evident, as in rehydration with water vapour and mists, that rates of less than $10^{-2} \mathrm{mg}$. water/sec./mg. dry matter were detrimental, although the relative damage at these rates was very variable. The viable counts obtained at the optimum rehydration rates were from about five to a hundred-fold greater than those given by rapid pipetting of $0.25 \mathrm{ml}$. water on to the dried suspensions.

Rehydration at various temperatures. The effect of the temperature of rehydration of Vibrio metchnikovi was examined in several fluids; Fig. 7 summarizes the results of an experiment in which rehydration was carried out at four temperatures in $2 \mathrm{ml}$. of each of four fluids. The actual rehydration operations at each temperature were carried out in a constant-temperature room, at the appropriate temperature, all equipment and solutions being at the operating temperature. After the initial rehydration the ampoules were transferred to room temperature before further dilutions in saline were made. Inspection of Fig. 7 shows that for each fluid, rehydration at $37^{\circ}$ resulted in lower viable counts than at $0^{\circ}, 11^{\circ}$ or $22^{\circ}$. For the two most concentrated solutions, however, the adverse effect at $37^{\circ}$ was decreased. Other experiments 
showed that rehydration in $\mathbf{0 . 2} \mathrm{ml}$. also decreased the deleterious effects of rehydration at $37^{\circ}$. There was no indication that rehydration at $0^{\circ}$ led to any decrease in viability.

Other experiments with Vibrio metchnikovi showed that the lethal effects which followed the transfer of undried organisms to hypotonic solutions were also much greater at $37^{\circ}$ than at the lower temperatures. It was not possible to relate these changes in viability to loss of substances which absorbed at wavelength $256 \mathrm{~m} \mu$, since in all cases the concentration of these substances in the cell-free supernatant fluids was much greater than with other bacteria studied. This large amount of leakage was doubtless a consequence of the rather large mortality which occurred with all drying and rehydration treatments.

\section{Experiments with other organisms}

The influence of rehydration on a wide range of organisms was examined mainly by reconstituting $\mathbf{0 . 2} \mathrm{ml}$. replicate samples of dried suspensions in different volumes of water. Viable counts of suspensions of Pasteurella multocida, Salmonella oranienburg, S. newport, Escherichia coli, Pseudomonas fluorescens, Serratia marcescens, Bacillus subtilis, $\boldsymbol{B}$. stearothermophilus (spores), Lactobacillus casei, Streptococcus lactis and Staphylococcus aureus were unaffected by differences of 0.25 to $16 \mathrm{ml}$. in the volume of water used for reconstitution, even when prolonged storage had decreased the overall viability to less than one-thousandth of the original value. On the other hand,

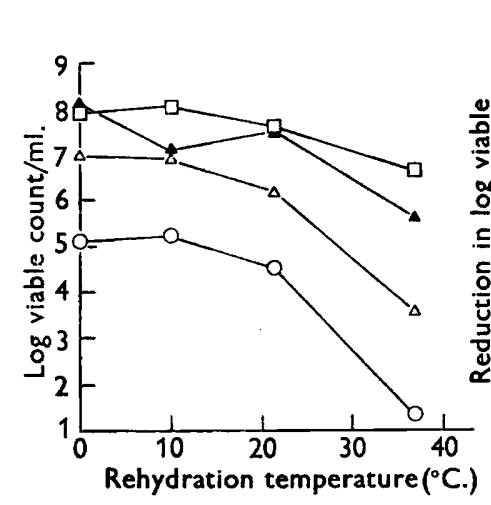

Fig. 7

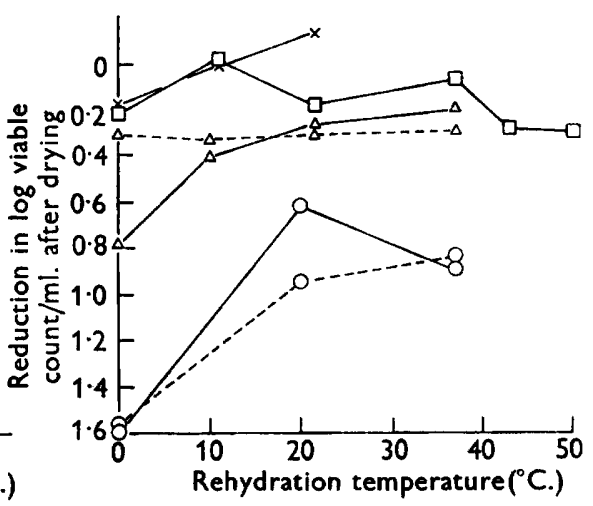

Fig. 8

Fig. 7. Survival of dried Vibrio metchnikovi as a function of the rehydration temperature. Viable counts from $0.2 \mathrm{ml}$. samples of a culture, dried in $0.1 \mathrm{M}$-sorbitol, and reconstituted at various temperatures with $2 \mathrm{ml}$. of: $\square$, sucrose solution $\left(0.980 a_{\bar{v}}[1.03\right.$ molal $\left.]\right) ; \Delta$, $\mathrm{NaCl}$ solution (0.980 $\left.a_{w}[0.61 \mathrm{molal}]\right) ; \triangle, \mathrm{NaCl}$ solution $\left(0.995 a_{w}[0 \cdot 15\right.$ molal $\left.]\right) ; 0$, distilled water.

Fig. 8. Survival of dried suspensions of various organisms as a function of the rehydration temperature. Viable counts from $0.2 \mathrm{ml}$. samples of cultures, dried in $0.1 \mathrm{M}$-sorbitol, and reconstituted at various temperatures with $2 \mathrm{ml}$. rehydrating fluid. $\times$, Staphylococcus aureus; $\square$, Saccharomyces cerevisiae; $\triangle$, Serratia marcescens; $O$, Escherichia coli; strain $B$. The solid lines represent rehydration with distilled water, and the broken lines $\mathrm{NaCl}$ solution $\left(0.960 a_{w}[1.2 \mathrm{molal}]\right.$ for Serratia marcescens and 0.980 $a_{w}$ 0.61 molal] for $\boldsymbol{E}$. coli). 
suspensions of Mycoplasma mycoides dried in peptic digest + serum mixtures with added sucrose, gave viable counts which were up to 1000 times greater when the volume of water used was decreased from $2 \cdot 0$ to $0.25 \mathrm{ml}$. Similar comparisons for coliphages $\mathrm{T} 2$ and $\mathrm{T} 5$ dried from various media gave counts which were up to 100 times greater for the smaller volume, although with coliphage T2 the results varied somewhat in different suspending fluids.

In view of the results of Herrera et al. (1956) some tests were made with the rehydration of Saccharomyces cerevisiae and Serratia marcescens at different temperatures. The results, together with those for other experiments with Escherichia coli and Staphylococcus aureus, are summarized in Fig. 8, from which it may be seen that rehydration in cold water was disadvantageous for all three bacteria, but that no such effect was observed with the yeast. The damaging effect of rehydrating $S$. marcescens in water at $0^{\circ}$ was cancelled by rehydration in $\mathrm{NaCl}$ solution; this was not so for $E$. coli. Of the three bacteria only $S$. aureus showed any consistent increase in leakage of $256 \mathrm{~m} \mu$-absorbing materials after rehydration in cold water, the losses at $0^{\circ}$ being some $4-5$ times greater than those observed at $\mathbf{2 2}^{\circ}$. These results are, therefore, in the direction expected from the report of Sant \& Peterson (1958) and contrast with the effect of temperature previously found with Vibrio metchnikovi. The different responses of the latter organism and of $S$. marcescens were confirmed in an experiment in which mixtures of the two organisms were dried together and replicate ampoules rehydrated at 0 and $37^{\circ}$. In comparison with the counts after rehydration at $0^{\circ}$, rehydration at $37^{\circ}$ increased the population of $S$. marcescens by c. $30 \%$ and decreased that of $V$. metchnikovi by c. 80-85\%.

\section{DISCUSSION}

It can be assumed that in restoring water to dried organisms there will be some finite rate of rehydration at which the damage to the cells will be least. Very slow rates will increase the damage due to storage in the presence of some water (Monk \& McCaffrey, 1957; Scott, 1958); extremely fast rates will doubtless tend to disrupt cellular components as a result of differential expansion or swelling. A problem of rehydration is, therefore, to define the rate of rehydration most suitable for retaining the functional and structural integrity of the organism. The present paper provides some experimental evidence which suggests that the rate of rehydration is important, at least for Vibrio metchnikovi. The rates shown in Fig. 6 are, of course, mean values based on the discontinuous addition of water, and they should not be expected to apply when water is added continuously. It may be noted, however, that the trends were not greatly affected by a tenfold difference in drop size. For the conditions of these experiments the best survival resulted when the mean rates of addition of water were between 0.01 and $0.1 \mathrm{mg} . / \mathrm{sec} . / \mathrm{mg}$. dry matter, or between 1 and $10 \%$ of the dry matter/sec. For a fully hydrated organism containing water equal to $300 \%$ of the dry weight, the time required to restore this amount of water would then be from 30 to 300 sec. Although only very approximate, these estimates show the order of magnitude of the most 
favourable rates in comparison with the 'instantaneous' rates attainable with liquid water. The results with aqueous solutions (Figs. 3, 5) furnish only suggestive evidence that the rate of rehydration is important, and they cannot be used to estimate the most beneficial water flux. The experiments with aqueous solutions have shown, however, that for Vibrio metchnikovi exposure to dilute solutions is a major cause of death when relatively large volumes of water or dilute solutions are employed. The fact that dried organisms proved to be more susceptible to dilute solutions than undried organisms (Fig. 4) is of some interest, although there is no evidence that this is true for organisms other than $V$. metchnikovi. It is of interest that the most

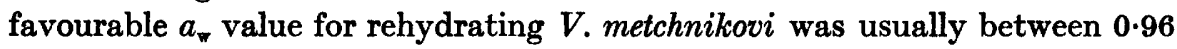
and $\mathbf{0 . 9 8}$, considerably less than the optimum for growth, which was shown by Marshall \& Scott (1958) to be about $\mathbf{0 . 9 9 5}$ for this osmotically sensitive organism. Iljin (1953) discussed the need to control the rate of rehydration of dried plant cells, and stated that rehydration in sucrose solution was beneficial.

The methods used to assess the integrity of the cells will doubtless affect the probability of detecting any damage which the organisms may suffer during rehydration. For instance, Mitchell \& Enright (1957) demonstrated that the fermenting and leavening ability of dried yeast was destroyed by certain rehydration procedures which did not impair viability; special rehydration procedures were necessary for retention of fermenting and leavening properties. Similarly, Sant \& Peterson (1958) showed that rehydration treatments which caused only moderate leakage from yeast cells did not necessarily affect viability. The present results show that some of the bacteria whose viable counts were unaffected by rehydration in different volumes of water were, nevertheless, somewhat decreased in numbers by rehydration at low temperatures (Fig. 8). The greater tolerance exhibited by some organisms may simply indicate differences in degree rather than in the nature of their requirements. Perhaps conditions of rehydration which are essential for sensitive species will also decrease the chances of damage to more resistant organisms. On the other hand, evidence for differential responses to the temperature of rehydration (Figs. 7,8 ) suggests that there may be real differences in the requirements of different organisms. Further work may show whether or not this is so, and may explain the possible interconnexion between solute requirements, temperature, $\mathrm{pH}$ value and the previous treatment of the organisms, as revealed by Wasserman \& Hopkins (1957) and by some of the results presented above. From a practical point of view it is clear that successful rehydration of some micro-organisms will be aided by rehydrating with limited volumes of concentrated solutions or infusions and, where rehydration with liquid water is essential, by using no more water than is necessary, and controlling the rate of its addition.

The technical assistance of Miss Naomi Waters is gratefully acknowledged. 


\section{REFERENCES}

AnNear, D. I. (1956). The preservation of bacteria by drying in peptone plugs. J. Hyg., Camb. 54, 487.

Carr, J. G. \& Harris, R. J. C. (1951). Preservation of the agent of the Rous sarcoma No. 1 by freeze-drying. Brit. J. Cancer, $5,95$.

Fry, R. M. \& Greaves, R. I. N. (1951). The survival of bacteria during and after drying. J. Hyg., Camb. 49, 220.

Greiff, D., Buumenthal, H., Chiga, M. \& Pinkerton, H. (1954). The effects on biological materials of freezing and drying by vacuum sublimation. II. The effect on influenza virus. J. exp. Med. 100, 89.

Haskins, R. H. (1957). Factors affecting survival of lyophilized fungal spores and cells. Canad. J. Microbiol. 3, 477.

Hr.ckly, R. J., Anderson, A. W. \& Rockenmacher, M. (1958). Lyophilization of Pasteurella pestis. Appl. Microbiol. 6, 255.

Herrera, T., Peterson, W. H., Cooper, E. J. \& Peppler, H. J. (1956). Loss of cell constituents on reconstitution of active dry yeast. Arch. Biochem. Biophys. 63,131 .

Higainbottom, C. (1945). The technique of the bacteriological examination of dried milk. J. Dairy Res. 14, 184.

Hiscox, E. R. (1945). The effect of the method of reconstitution and of the temperature of incubation on the plate count of spray-dried milk powder. J. Dairy Res. 14, 175.

Hutton, R. S., Hilmoe, R. J. \& Roberts, J. L. (1951). Some physical factors that influenee the survival of Brucella abortus during freeze-drying. J. Bact. 61, 309.

ILJIN, W. S. (1953). Causes of death of plants as a consequence of loss of water; conservation of life in desiccated tissue. Bull. Torrey bot. Cl. 80, 166.

Kraft, L. M. \& Pollard, E. C. (1954). Lyophilization of poliomyelitis virus. Heat inactivation of dry M.E.F.I. virus. Proc. Soc. exp. Biol., N.Y. 86, 306.

Marshall, B. J. \& Scotr, W. J. (1958). The water relations of Vibrio metchnikovi at $30^{\circ}$. Aust. J. Biol. Sci. 11, 171.

Mazur, P. \& Weston, W. H. (1956). The effects of spray-drying on the viability of fungus spores. J. Bact. 71, 257.

Medical Research Council (1958). Memorandum No. 35, The National Collection of Type Cultures: Catalogue of Species. London: H.M.S.O.

MrLes, A. A. \& Misna, S. S. (1938). The estimation of the bactericidal power of blood. J. Hyg., Camb. 38, 732.

Mrtcheld, J. H., Jr. \& ENRight, J. J. (1957). Effect of low moisture levels on the thermostability of active dry yeast. Food Tech., Champaign, 11, 359.

Mrtcheld, P. \& Moyle, J. (1956). Osmotic function and structure in bacteria, in Bacterial Anatomy, Symp. Soc. gen. Microbiol. 6, 150.

Monk, G. W. \& McCAFrney, P. A. (1957). Effect of sorbed water on the death rate of washed Serratia marcescens. J. Bact. 73, 85 .

Proom, H. \& Hemmons, L. M. (1949). The drying and preservation of bacterial cultures. J. gen. Microbiol. 3, 7.

Rhodes, M. (1950). Viability of dried bacterial cultures. J. gen. Microbiol. 4, 450.

Robinson, R. A. \& Stokes, R. H. (1955). Electrolyte Solutions. London: Butterworth's Scientific Publications.

Sant, R. K. \& Peterson, W. H. (1958). Factors affecting loss of nitrogen and fermenting power of rehydrated active dry yeast. Food Tech., Champaign, 12, 359.

Scatchard, G., Hamer, W. J. \& Wood, S. E. (1938). Isotonic solutions. I. The chemical potential of water in aqueous solutions of sodium chloride, potassium chloride, sulfuric acid, sucrose, urea and glycerol at $25^{\circ}$. J. Amer. chem. Soc. 60, 3061 . 
Scotr, W. J. (1953). Water relations of Staphylococcus aureus at $30^{\circ}$. Aust. J. biol. Sci. 6, 549.

Scotr, W. J. (1958). The effect of residual water on the survival of dried bacteria during storage. J. gen. Microbiol. 19, 624 .

SPECK, M. L. \& MYERS, R. P. (1946). The viability of dried skim milk cultures of Lactobacillus bulgaricus as affected by temperature of reconstitution. J. Bact. $52,657$.

StaMp, Lond (1947). The preservation of bacteria by drying. J. gen. Microbiol. 1, 251.

Wasserman, A. E. \& Hopkins, W. J. (1957). Studies on the recovery of viable cells of freeze-dried Serratia marcescens. Appl. Microbiol. 5, 295.

(Received 13 January 1959) 